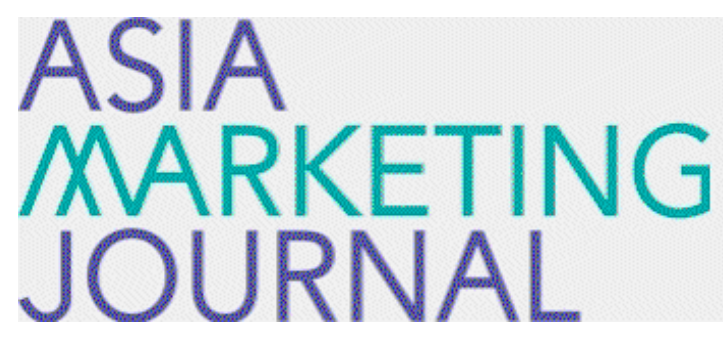

ASIA MARKETING JOURNAL

Volume 22 | Issue 4

Article 2

$1-31-2021$

\title{
Is BTS Different? Shared Episodes on SNS as a Good Indicator for Celebrity Endorsed Ad Effects
}

Kyunghee Bu

Whoe Whun Kim

Follow this and additional works at: https://amj.kma.re.kr/journal

Part of the Marketing Commons

\section{Recommended Citation}

Bu, Kyunghee and Kim, Whoe Whun (2021) "Is BTS Different? Shared Episodes on SNS as a Good Indicator for Celebrity Endorsed Ad Effects," Asia Marketing Journal: Vol. 22 : Iss. 4 , Article 2.

Available at: https://doi.org/10.15830/amj.2020.22.4.27

This Article is brought to you for free and open access by Asia Marketing Journal. It has been accepted for inclusion in Asia Marketing Journal by an authorized editor of Asia Marketing Journal. 


\title{
Is BTS Different? \\ Shared Episodes on SNS as a Good Indicator for Celebrity Endorsed Ad Effects*
}

\author{
Kyunghee $\mathrm{Bu}^{* *}$ \\ Whoe Whun Kim***
}

\begin{abstract}
This study examines the effects of celebrity endorsed advertising from a new perspective of the prior research that emphasizes the matchup between the brand and the celebrity. Due to the recent sharing experiences of the celebrity and their fans on SNS, it is hypothesized that the shared stories would impact viewers' responses that are often expressed in their likes, dislikes, shares and comments on SNS. In this study, the episodic type of advertising is hypothesized to have more favorable and active responses from viewers than the typical celebrity image-focused ads would have. By crawling and analyzing viewers' responses on YouTube toward 12 BTS endorsed ads, the hypotheses are confirmed as higher ratio of likes, lower ratio of dislikes and significantly higher ratio of comments over both total views and total likes were found. For the rationale behind, total 1800 comments were categorized into 4 major content types such as attached, experiential, empathic and self-related ones that are all considered as important factors influencing the strong ad effect. The results showed that the episodic ads have marginally more emotional comments than the celeb image ads. The difference was only found in experiential and empathic responses but not in self-related responses. Contrary to the hypothesis, the comments expressing attachment were found more for the celebrity imagefocused ads than the episodic ones. It does not seem to suggest that the celebrity image focused ads are better to capture viewers' attachment towards the celebrity and the ad endorsed, but that the episodic ads draw viewers into relatively deeper level of attachment such as empathy by perceiving the authenticity of the celebrity and the brand. In conclusion, the shared stories on SNS can be a factor in the match-up theory on celebrity endorsed ad effects.
\end{abstract}

Keywords: celebrity endorsed ad effects, episodic ads, image ads, BTS, shared experience

\footnotetext{
* The work reported in this paper was conducted during the sabbatical year of Kwangwoon University in 2017

** Professor at Kwangwoon University (khbu@kw.ac.kr), First and Corresponding Author

*** Senior Manager at SBS (finn@sbs.co.kr)
} 


\section{Statement of intended contribution}

- What is the marketing-relevant research question addressed in your manuscript and how does the research address it?

Celebrity endorsed advertising markets are growing as large as 10 billion USD, including the fast growing SNS influencers. However, few studies have looked into the changes on SNS where more open and disclosed communications between the celebrity and the consumers are prevalent. This study examines the changes in viewers' information gates such as SNS to better understand the ad effects that have been a major research topic in marketing for long.

- How does your research add to the academic marketing discipline's existing knowledge on the topic?

This study posits a newer perspective to include the context SNS generated in understanding celebrity endorsed advertising effect. Recently, the match between the brand and the celeb has been the major subject in the studies as well as the earlier findings on expertise, trustworthiness and attractiveness as the main factors influencing. However, both lines of research miss out the fact that consumers can get quite a lot of perceptions through SNS where celebrities disclose their personalities in various episodes. Thus, they can sense out the authenticity of the celebrity easier than before, which will result in their perception toward the ad and the brand. In addition, by using all BTS endorsed ads, all other possible variables such as brand level, product types, celebrities' personality and images can be controlled.

- Which non-academic stakeholder would find value in your manuscripts (e.g. for-profit firms, non-profit organizations, governmental agencies and policy makers, and/or other non-governmental societal stakeholders engaged with marketing)? How might your paper change the thinking and/or behaviors of these stakeholder(s)?

The old theories on celebrity endorsed ads limit the creativity of the contents by emphasizing the risks that celebrities would evoke. Since celebrities are perceived to be vulnerable to the risks such as scandals, aggressive fans or antis, companies tend to focus on their pictural images of physical attractiveness or their expertise than the verbal expressions or stories. This tactic may be an over-reaction in the era of SNS. For, viewers may process the ad with full knowledge or the experiences on the celebrities' personalities and attitudes. Thus, practitioners can utilize viewers' prior experiences in the stories, personalities and affects shared through SNS in ads, so viewers can consume the ad contents enough 
for the attachment to be transferred to the ad and the brand.

Celebrity endorsement has grown remarkably for the last decade (Schimmelpfennig, 2018; Choi, Lee, and Kim, 2015). Especially due to the thrust of various social media, advertisers tend to consider celebrity as the best ambassador for their brand, in order to avoid the clutters (Gupta, 2017). In fact, $42 \%$ of the total South Korea ads (along with 61\% in China, 54\% in Japan, 25\% in U.S.) were celebrity endorsed in 2020. The celebrity ad market is expected as huge as 9.7billion $\$$ in 2020 (Kantar Millward Brown, China BrandZ, and CelebrityZ, 2020), including the influencers in SNS platforms such as YouTube, which makes the total market size bigger than ever.

The global artist group BTS is recently endorsing a massage chair brand 'Bodyfriend', which makes non-fan community frequently raise a question. The concerns such as "Shouldn't superstar like BTS endorse more prestigious brand than that?" or "Would healthy young targets feel about a massage chair?" lie mostly in the mismatch between the brand and the endorser. The questions look reasonable since the congruency between a brand and its endorser has recently been debated and suggested as the most influencing factor on the endorsement effect. Above all the other factors such as the trustworthiness and attractiveness of the endorser, endorsers' relevance with the brand has been a major issue in persuasion research for a decade. Therefore, the main skepticism about BTS's Bodyfriend ads mostly reflects on near zero-congruency between the two.

Not surprisingly to the fans, however, the Bodyfriend endorsement effect is tremendous. Right after the ads, the Bodyfriend achieved the best sales ever in the company's history with over 60 million dollars and 14.3\% increase on parent day period compared to the sales of the same day a year before. So, it poses a question on what the reasons behind the ingredient of BTS endorsement are. Is the effect just because of their popularity? Then why did the previous studies report less effects of low-relevancy ad with other popular celebs? Is the BTS effect just for short-term return of sales but not for the long-term image association with the brand? Or, are their portrayals in the ads different from usual image portrayals of celebrity ads?

The BTS ad effects seem somewhat different from the typical "celeb effects", which usually come from the celebrity image association. It seems more related to a well-known episode in which the massage chair was given to BTS as a gift by the fan vote for a media event in 2017 after BTS accidentally had slipped their wish to have one for the quick recovery from their long dance practices in one of their earlier SNS clips. Thus, the massage chair could be more than just a mismatched brand. This episode is hardly known to most audience, but BTS 
fans could feel the authenticity of the endorsement by noticing the portrayed stories in the Bodyfirend ads as their shared stories through SNS. The brand Bodyfriend is not the only case reporting the tremendous effect of BTS ads. Considering their multiple brand endorsements across various brands, it is certainly necessary to examine the other factors working at this effect.

The BTS ad effect is particularly interesting because researchers on this topic mostly agree that the effect of multiple brand endorsements by celebrities tends to decrease as the endorsement multiplies (Tripp, Jensen, and Carlson, 1994). Ilicic and Webster (2014) explain that the effect eclipses especially when the celebrity overshadows the endorsed brand and weakens the associative link between the celebrity and the brand. According to Campbell and Kirmani(2000), the consumers' doubt of authenticity in multiple endorsements is one of the reasons for the decreasing effects. To compensate the decreases with multiple endorsements, there must be other factors strengthening the authenticity such as brand essence, brand heritage, realistic plot, or message credibility in advertising (Maren, Wiegand, and Reinartz, 2019). If we exclude the brand-related factors, realistic and credible ad contents are subjects to examine further, to find any element preventing the diminishing effects of multiple endorsement.

Viewers' involvement in SNS is assumed to increase their realistic perception of the endorsed $\mathrm{ad}$, which would eventually lead to their sense of endorser's authenticity. In particular, the sharing experiences of various episodes through SNS seem to play an important role in absorbing the ad contents without doubts. Few studies have examined the shared experiences between the celeb and the viewer, which is assumed to increase the authenticity perception towards the celebrity and the brand. Especially due to the flourishing SNS communications where fans are exposed to various episodes of their celebs, an investigation on the effect needs a new attention. In conclusion, this study tries to appraise the factors that have been missed out in celebrity endorsement literature, such as the effect of shared experience on SNS.

\section{Literature Review}

Studies on celebrity endorsers mostly agree on their trustworthiness, attractiveness and relevance to brand as the most important factors influencing consumers' attitude toward the brand (Schimmelpfennig, 2018 for review). The definition of celebrity ad effect, however, can be diverse depending on the purpose of the ad campaign. For example, the goal of the campaign can be an instant growth of sales, the product/brand awareness, ad/brand likings, or the brand image association. Among these, matching their image with brand has particularly been emphasized in making a good brand 
association. In particular, the congruency between the brand and the endorser draws more attention than ever as a way of differentiating the brand from competitors in the cluttered market now (Erdogan, Baker, and Tagg, 2001).

Researches have shown that a mismatch between the celebrity and the brand results in negative consumer attitude towards the brand (Ilicic and Webster, 2014; Kamins and Gupta, 1994; Lynch \& Schuler, 1994) and dissuasion (Rossiter and Smidts, 2012). However, it is also noted that simple image congruence is found to be ineffective, if it is not supported by other factors blending the two. For example, even a small connection such as the country of origin can strengthen the attachment to the brand (Gupta, 2017). Also, the consumer brand attitude becomes weak when the connection between the celebrity and brand diminishes, mainly by focusing too much on celebrity than on the brand. In the study, the researchers have suggested that the association between the celeb and the audience can be another important factor affecting the endorsement effects; a strong viewer attachment to the endorser resulting in higher brand attitude than a weak attachment (Ilicic and Webster, 2014). Not just relevancy but strength of the 3-way connection among the celebs, the brands and the viewers seem to make the impact different.

One obstacle to enhancing the strength between celebs and viewers is the intention-to-persuade perception of the consumers toward advertising
(Friedstad and Wright, 1994). Even with a little doubt about authenticity, consumers can easily lower their likings to the ad and the brand (Obermiller and Spangenberg, 1998), regardless of the credibility of the celebs. In fact, more recent research suggests that consumers naturally evaluate the authenticity of an ad, with more authentic ads being connected to more favorable ad evaluations (Miller, 2014). And most relevantly, consumers tend to search for authentic brands by trusting people such as endorsers beyond brands or logos (Cornelis and Peter, 2017), which suggests the viewers' perceptions on the endorsers' authenticity are underrated as the important factor influencing ad effects.

A study finds that higher perceived brand authenticity produces better outcomes such as word of mouth effects and emotional brand attachment (Morhart et al., 2015). It is not surprising that higher celebs authenticity would also generate stronger ad effects. A recent study has shown that just a little alteration of images can make viewers doubt authenticity and result in lowering their likings to the ads, which gives an important implication in the ad effects (Kim \&Johnson, 2020). The damage done to authenticity perception is particularly huge because the images of the models and the meaning behind the images are found to be closely related to consumer image and selfesteem (Beverland et al., 2008; Cornelis and Peter, 2017; Grayson and Martinec, 2004). 
The perspective on authenticity is based on reliability and credibility which are found to be best effects in sales (Popescu, 2014). This may be the reason that the experts and the authorities often endorse certain types of product categories such as cars, high tech products and finance related categories (Biswas, Biswas and Das, 2006) in which celeb credibility is a must for ad effects. Even though multiple studies show that the effectiveness of different endorser types depends on the category of the advertised product (Till and Busler, 2000; Kim, Wang, and Ahn, 2013), the category specific endorsement seems to collapse with the emergence of SNS such as YouTube, Facebook, and Instagram in the celebrity scene. Rather than aspiring an image of celebrity to be associated with their brands, companies look more for good stories in those platforms where audience can directly react and express their feelings and thoughts on the ads, hoping their attachment to the celeb grow to the brand.

Studies have found that contents perceived as authentic will also likely increase brand trust (Bazaar Voice, 2018) in addition to the authentic personality of the celebrity, attitudes, and purchase intentions (Cornelis and Peter, 2017). Since the perception of authenticity is subjective and dependent on context (Miller, 2014), the fact that viewers experience and understand the context behind the ad contents requires a different perspective in studying celeb-ad effects. Especially when the endorsers disclose their emotions and the behaviors shown on SNS are similarly depicted in ads, the credibility would sharply increase. In addition, authentic advertising stimulates brand trust (Anderberg and Morris, 2006), helps consumers connect with the brand (Holmes, 2015), triggers feelings of sympathy or empathy (Stern, 1994), and reduces consumer skepticism toward ads (Poetzsch, 2014). Despite the distinct importance of the concept, however, authenticity has been missed out in advertising (Miller, 2014; Wang, 1999), and questions remain about what ad elements are necessary to deliver authenticity to a viewer (Beverland, et al., 2008). Recent trends in brands' dependency on SNS influencers evidence how important the personal level of actual experiences is for the ad effect. The shared experiences can be an important factor eliciting the initial involvement in the episodic ad type because it makes the content "our" story instead of "theirs". Moreover, since the "intention to persuade" perception towards advertising tends to interfere in the motivation to process any unfamiliar contents or stories in ads (Campbell and Kirmani, 2000), the shared experiences can result in avoiding the low trustworthiness. As a whole, either dramatized stories or episodes in ads not only attract the audience by their nature but build a stronger authenticity if they are already shared contents. 


\section{Research Hypotheses}

The question of this study is whether the ad type makes the effect different besides other factors related to celeb ad effects. For example, if shared stories or episodes are cued in ads, they are expected to have a greater impact on the perception of the ads' authenticity by the viewers than those without the cue. Particularly, if the viewers know the back story through sharing experiences, ads portraying similar stories will get high involvement. In that case, besides the congruency between the celebrity and the brand endorsed, advertising types will have a role in ad effects. The responses and comments would be different for the episode depicting shared stories from the image-match up ads. The stories depicted with the shared episode would have more chance to get viewer's involvement, which would result in more active responses such as likes, shares and making reaction clips.

The association between the celeb and the audience can also be the important factors affecting the endorsement effects because a strong viewer attachment to the endorser resulting in higher brand attitude than a weak attachment, as Ilicic and Webster (2014) found in their study. It is noteworthy that not just the congruency but the strength of the connection between the celebrity and the consumer makes the impact different (Rossiter and Smidts, 2012).
If the consumer finds themselves connected and relevant to the depicted episodes through celebrity, they will not only pay more attention but want to show more active responses by their heightened attachment toward the celebrity. In addition, if viewers can personally relate to the story in ads based on their SNS experiences, it can not only create positive sentiment but lead to stronger self-involvement in the ads, which would result in liking the brands by praising, sharing and writing good words for the brand in the ads. The sharing experiences can also elicit viewers' emphatic responses for the episodes in ads. It is an important question because the typical celeb image-focused on-air ads depends more on celeb's personalities and traits to the brand (Bergkvist, 2017) than the relationship between the celebrities and the viewers. However, the viewers' sharing the same feeling in SNS is presumed to work best in creating empathic responses towards the stories, the celebrities and the brand compared to the image- matching ad. With this rationale suggesting that the shared experiences make the episodic ads more persuasive than other ad types such as celeb image centered ad, this study has research hypotheses as follows.

H1: The episodic BTS ads will have more active responses than their image focused ads.

H1a: There will be higher ratio of comments over total views for episodic BTS 
ads than for their image focused ads.

H1b: There will be higher ratio of reaction clips over total views for the episodic BTS ads than for their image ads.

H1c: There will be higher ratio of share over total views in SNS for the episodic BTS ads than for their image ads.

H2: The episodic BTS ads will have more positive sentiments than their image focused ads.

H2a: There will be higher ratio of likes over total views for episodic BTS ads than for their image focused ads.

H2b: There will be lower ratio of dislikes over total views for episodic BTS ads than for their image focused ads.

H2c: There will be higher positive sentiments for episodic BTS ads than for their image focused ads.

Lastly, if the episodic ads depict the shared stories, there will be many more comments sharing the stories, resulting in attachment toward them. Furthermore, there would be more empathic feelings in the comments for episodic ads than for image-focused ads, which is known to be most effective out of various emotional expressions towards advertising ( $\mathrm{Bu}$, 1997).

H3: There will be more shared comments for episodic BTS ads than for their image focused ads.

H3a: There will be more experiential comments for episodic BTS ads than for their image focused ads.

H3b: There will more attachment-related comments for episodic BTS ads than for their image focused ads.

H3c: There will be more empathic comments for episodic BTS ads than for their image focused ads.

H3d: There will be more self-related comments for episodic BTS ads than for their image focused ads.

\section{Research Method}

To verify the hypotheses, the SNS responses for each BTS ad type were analyzed. The whole period of response data from the on-air day 1 are crawled from SNS platforms such as YouTube and Twitter where their fandom are most active in terms of the size; 30,764 million twitter follower and 40,4 million subscriber, respectively.

\subsection{Brands endorsed}

Maren, Wiegand, and Reinartz (2019) found that showing a realistic plot and presenting a credible message are more strongly associated with advertising effectiveness for utilitarian 
(vs. hedonic) product categories. All brands endorsed by BTS were categorized by the product types based on FCB Grid. Using only BTS ads has advantages: BTS covers most of the categories in products and ad types, which is good to control the various celebrity- and brand-related traits. Even though the price of the product endorsed can also be controlled in only BTS ads, it is still an important variable for ad effect. Therefore, we tried to include products with various price levels as possible. Also, BTS ads for both functional and hedonic products are selected in this study to control product/brand traits.

The BTS ads are also selected based on the recent on-air date to control the size of the fandom. BTS fandom has grown drastically after 2017 America Music Award and 2018 Billboard Music Award, from a little less than 5 million to 38.9 million (see for all the endorsed brands and PR their ads in the Appendix 1). Therefore, ads aired after 2018 are mainly considered as the candidates for this study. The relatively recent 12 ads from 6 brands, 3 functional and 3 hedonic categories mixed during this period are selected for the analyses as shown in Table 1.

\subsection{Categorization of Ad Types}

The ad types are categorized as episodic ads (dramatized) versus image-focused ads. Since their debut year 2013, the total ads endorsed by BTS are about 190 ads for 25 different brands. The typical portrayals of endorsers range from professional image for expertness to chick and fashionable image for attractiveness to familiar and heartful image for trustworthiness. However, the studies missed the fact that the three are not mutually exclusive. Rather than focusing on the celebs portrayed images, it seems to be more relevant to divide advertising types into two: visual image focused ads frequently shown in celeb ads and episodic/ dramatized ads type to support the hypotheses in this study.

The selection of ads is mainly based on whether the same brand has two different types of ads. For example, BTS recently has become a global endorser for Fila which is excluded from this study because their ads are all image focused ads so far. Ads with an individual member are also excluded to rule out the possibility of individual fandom size. The criteria of selecting episodic ads are mainly based on

〈Table 1〉 Selected BTS endorsed brands by Product Categories

\begin{tabular}{l|l}
\hline \multicolumn{1}{c|}{ Functional Products } & \multicolumn{1}{c}{ Hedonic Products } \\
\hline Car: Hyundai Pallisade & Fashion: Lotte Duty Free Shop, \\
$\begin{array}{l}\text { Phone: Samsung Galaxy S20/Galaxy Note 20 } \\
\text { Massage Chair: Bodyfriend }\end{array}$ & Sportswear: Puma \\
\hline
\end{tabular}


either whether the ad depicts any stories and episodes in BTS contents or whether the ad shows the distinct personality of each members, rather than shows their looks as most celebrity ads are depicted. Table 2 shows the selected ads with their campaign names and aired dates. It is especially good to have the same brands for both advertising types so that the brand, product and airdate factors are naturally controlled.

\subsection{Dependent Variables}

The measurements are first based on the engagement rate related ones such as like, share and comments. In addition, to examine more active responses from the viewers, number of reaction clips were also analyzed in each ad type. Initially, emotions from viewers' comments are all crawled and put to a sentiment analysis tool 'Google Bert'. However, it turned out that the tool is not trained for fandom, so it mistook the extremely positive sentiment such as "they are killing it", or "I am dead", or "My bias is JK" as very negative. Therefore, the comments were only analyzed in terms of the response types. For example, each comment was coded mainly as emotional expressions such as expressed attachment, experience, empathy and self-related ones. Two groups of 10 coders, total of 20 , coded the comments. The criteria to categorize the comments were fully given to the coders and the coder reliability was $r=.94, r=.87$, $r=.82$, and $r=92$, respectively for attachment, experiential, empathic and self-related ones. All dependent measures used in this study are listed in Table 3.

All dependent measurements on active engagement are self-explanatory with the provided frequencies of views and shares. However, the reaction clips from the YouTube reactors who upload all BTS contents were excluded from the frequency of reaction clips to verify the differences between the two different types of BTS endorsed advertising as this study hypothesizes. As for the comment content analyses, the coding norms were set up before the actual coding started. The comments are categorized mainly into 3 types based on Bu(1997)'s categorization which are based on Stout and Rust(1993)'s definition of emotion

〈Table 2〉 The advertising types among BTS endorsed ads

\begin{tabular}{l|c|l|c}
\hline \multicolumn{1}{c|}{ Visual Image focused Ads } & On-Air Date & \multicolumn{1}{|c}{ Episodic/Dramatized Ads } & On-Air Date \\
\hline Galaxy S20: Galaxy X BTS & 2020.03 & GalaxyNote: The tailor shop & 2020.09 \\
HD Pallisade: Red Carpet & 2020.05 & Hyundai Pallisade: Camping & 2019.02 \\
Bodyfriend: BTS Forever & 2020.04 & Bodyfriend: Duty on precious & 2020.04 \\
\hline Puma: Basket & 2018.08 & Puma: Turin & 2018.03 \\
LDF : Let's do fun & 2019.03 & LDF: We wanna duty free life & 2020.09 \\
BR: Bangtan is Bera & 2020.07 & Baskin Robins: Bangtan is Bera & 2020.08 \\
\hline
\end{tabular}


〈Table 3〉 Dependent Measurements in SNS responses to BTS endorsed ads

\begin{tabular}{|c|c|c|}
\hline Active Behaviors & Positive Sentiment & Comment Content \\
\hline $\begin{array}{l}\% \text { of comments } \\
\% \text { of reaction clips } \\
\% \text { of share (retweet) } \\
\text { over likes }\end{array}$ & $\begin{array}{l}\% \text { of likes over total views } \\
\% \text { of dislikes over total views } \\
\% \text { of higher positive sentiment over } \\
\text { total comments }\end{array}$ & $\begin{array}{l}\% \text { of attachment responses } \\
\% \text { of experiential Responses } \\
\% \text { of empathic responses } \\
\% \text { of self-related responses }\end{array}$ \\
\hline
\end{tabular}

in advertising; attached, experiential and empathic emotion.

The attachment comment are the ones expressing excitement, high level of emotional expressions, praise, and admiration. For example, "OMG THEY LOOK SO GOOD I- / JIMIN IS SO HOT $\cdots$ ", or "Plus, Taehyung has stolen all our hearts and put them on his shirt!”. Experiential comments share their prior knowledge or story and often show analogy to BTS members' personality to the situation as seen in these examples: "And then I suddenly remembered the video JK posted on Tae's Birthday", "FINALLY SOMEONE TOOK RM'S HAND / I'm just surprised Namjoon didn't break the tent”, and Jinkook be like "In every lifetime I will find you... and fight you" are coded as experiential comments since the comments share prior experience of the incidents. Empathic comments are the ones that you feel, understand, see through experiences with newer perspectives as seen in the following examples: "why do I feel like crying/ Protect Kim NamJoon/ It's an MV actually", "Vmin : best friends, kind to each other Rap line : cool bros who encourage each other", and "You have come so far! I'm so proud of you! And congrats on being PUMA
Global Ambassador! *crying proudly at the corner of my room."

Self-motivated/self-related comments are also categorized other than the other 3 types. It reflects on herself/himself, and finds the sense of belongings such as "we" and "our" perceptions. "I'm going to do it. I'm going to achieve my goals, for me, for my family", *for bts*, for them to know that because of them, thousands of people would have changed for the better", "These are the types of ads that make me want to spend all my money on!", and "Dream Bigger, We will always be beyond the dream together" are the examples. There are just simple descriptions with little emotional expressions such as a single non-emotional word or a brief statement; "Someone know the song??" or "OK, I got it."

\section{Analyses and Results}

The results confirm our hypotheses 1 and 2 as demonstrated in Table 4 . which shows the total frequencies of various measurements. Since YouTube does not provide the data on the 
〈Table 4〉 The total frequency of views, likes, dislikes, and comments

\begin{tabular}{l|r|c}
\hline & Image Ads & Episodic Ads \\
\hline Total view & $21,720,184$ & $17,223,649$ \\
\hline Total likes & 609,759 & $1,223,621$ \\
\hline Total dislikes & 2492 & 3783 \\
\hline No. of comments & 11,812 & 43,517 \\
\hline Total likes to comments & 115,803 & 421,990 \\
\hline Total shares of comments & 3240 & 10,023 \\
\hline No. of Reaction clips & 39 & 86 \\
\hline
\end{tabular}

〈Figure 1〉 The ratio of likes/dislikes over total view by ad type

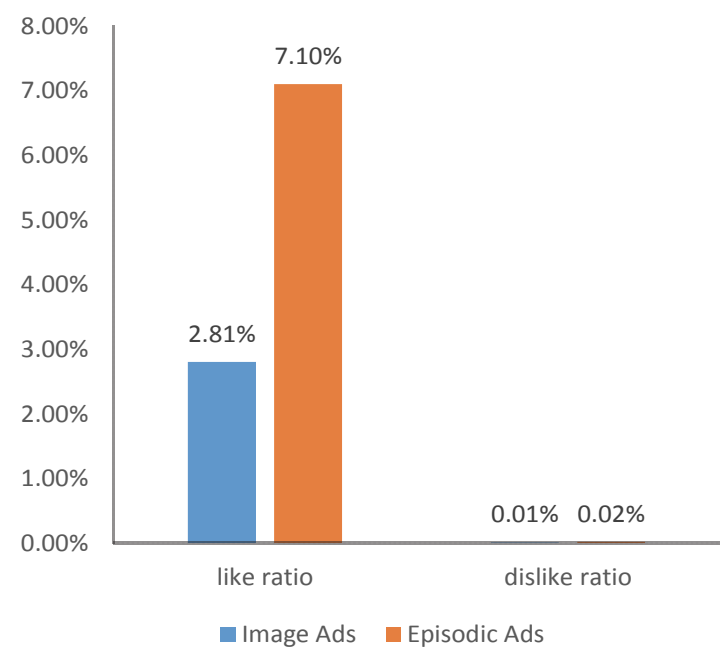

time of the views, likes and dislikes, the mere frequency may distort the reality. Thus, the ratio to total views was calculated for a fair comparison. Even though it is hard to run a statistical test on these measurements due to the nature of the data that only shows the total numbers per each ad, Fig.1 clearly shows that the episodic ads have higher ratio of likes and lower ratio of dislikes than the image-
〈Figure 2〉 The ratio of comments over total view and likes

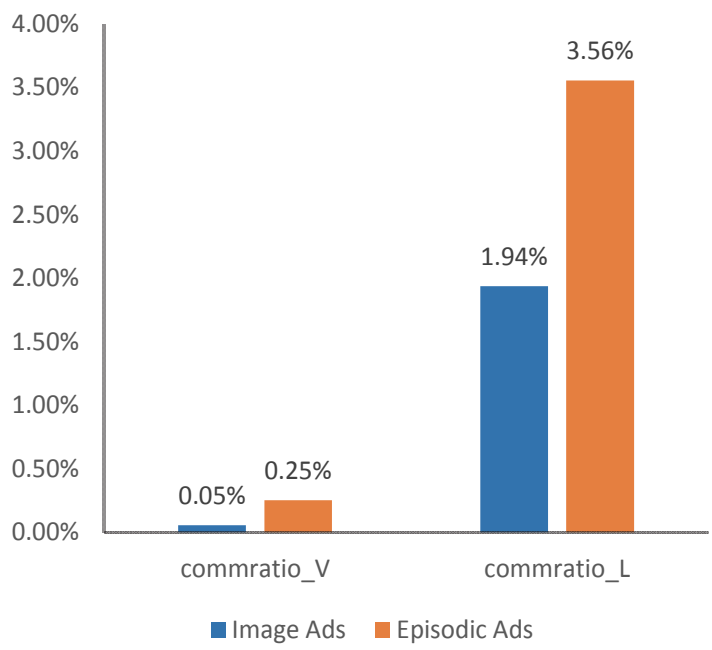

focused ads $(r=.93$ and $r=.084$, respectively $)$. Considering the size of the total view, the 1 percent difference is estimated to be about 200,000 more likes.

Especially, the comment ratio overboth total views (commratio_V) and total likes (commratio_L) showed significant differences between the two different types of advertising. In other words, there is a tendency that viewers 
tend to like more and dislike less the episodic ads than image ads. Moreover, viewers tend to comment more on episodic ads than images ads regardless of the size of the total views or likes. To find the sentiment difference, we tried Google Bert but it turned out that the software is not trained for a fandom context, resulting in mislabeled sentences. For example, it tends to consider many positive sentences in the fandom culture such as "they are killing it", "I am dead", or "My bias is JK" as very negative. Since it needs more than million data to train the software, it leaves the project for the future study. In spite of the limitation, the ratios of likes and dislikes confirm the hypothesis 2 .

For the hypothesis 3, a chi-square test was conducted to see the differences of the content of the comment type. There were more experiential and empathic comments on episodic BTS ads than on image-focused BTS ads whereas simpler descriptive and attachment comments on image-focused BTS ads than on episodic BTS ads. The results partially support our hypothesis in the way that attachment comments were hypothesized to be made more on episodic BTS ads, but the reverse was the case. Also, the frequency of self-related comments were almost same for both types of BTS endorsed ads.

As seen in table 5, the Pearson Chi-square analysis confirms hypothesis 3 , which supports the fact that there are significant differences among 6 comment types. However, linear by linear association shows marginally significant differences $(p<.092)$, which means that the differences in each category may not that much of differences.

〈Figure 3〉 The frequencies of the comment types by Ad type

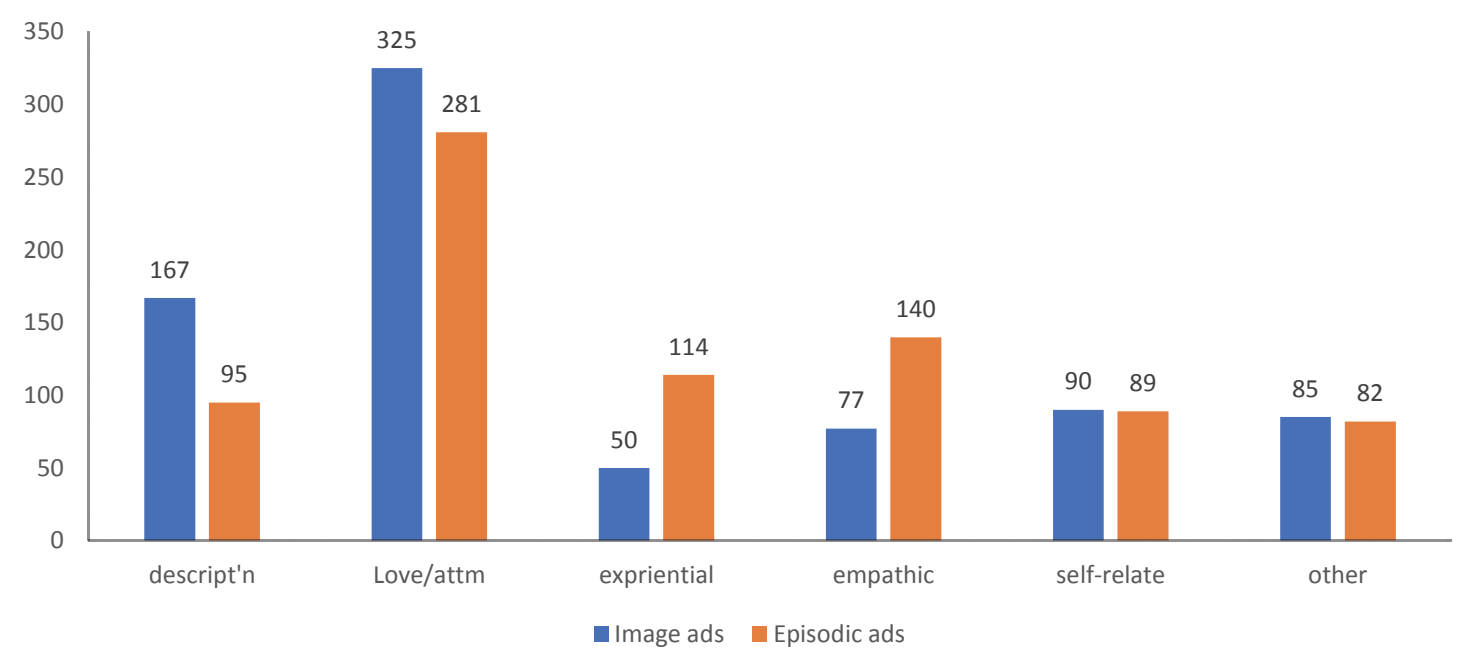


〈Table 5〉 Pearson Chi-square tests of 6 comment types between the two ad types

\begin{tabular}{l|c|c|c}
\hline & Value & df & $\begin{array}{c}\text { Asymptotoc Significance } \\
\text { (2-sided) }\end{array}$ \\
\hline Pearson Chi-Square & $45.483 a$ & 5 & 0.000 \\
\hline Likelihood Ratio & 46.744 & 5 & 0.000 \\
\hline Linear-by-Linear Association & 2.841 & 1 & 0.092 \\
\hline N of Valid Cases & 1798 & & \\
\hline
\end{tabular}

a. 0 cells $(0.0 \%)$ have expected count less than 5. The minimum Expected count is 75.96.

\section{Discussions}

This study looks into the effect of celebrity endorsed advertising by analyzing consumers' responses to the ads mostly on YouTube. Since consumers are exposed to ads on SNS more often than before, a newer perspective is adopted in this study; the shared experience between the celeb and the viewer through SNS as an important factor influencing the effects. With ads endorsed by BTS who are known to actively interact and share their thoughts and emotions with their fans on SNS, this study proved that the advertising types certainly bring different responses from viewers on SNS. The episodic BTS ads which depict more of the stories and personality of the celebrities are found to show more active responses and positive sentiments than the BTS image-focused ones are. To be specific, the results in this study show that the episodic ads have significantly higher ratio of likes and lower ratio of dislikes over total views than their image-focused ads, as hypothesized. Considering the fact that there are similar numbers of total views for both types of ads, the results strongly support the fact that the episodic ads can generate more positive effect and less negative sentiment than the celebrity image-focused ads.

Viewers not only liked more and disliked less of episodic ads but also showed far more active engagements than the other type ones, measured by the ratio of comments and of shares over likes. In addition, there were more reaction video clips for the episodic than for the image ads. The higher ratio of comments and of shares over likes for episodic ads suggests more than just difference in numbers. It is because commenting, sharing and making reaction video clips, compared to clicking likes, need extra efforts from the viewers' part. Since the consumers' active response is claimed to be associated with their high emotional involvement level which will eventually lead to their attachment toward the endorser and the brand, the results that episodic ads can generate more active consumer engagements on the contents firmly support the argument of this study. Again, under the same condition of BTS popularity, it 
implies that the episodic ad can contribute to viewer's active engagement at least on SNS context.

The analyses of the most liked comments of each ad types suggest that the difference were marginal for all 6 ad content types categorized ( $p<.092)$. However, a significant difference is found in each content types: ads depicting the shared experiences from SNS episodes work better in eliciting experiential and empathic responses whereas BTS image-focused ads have more comments of simple description and attached comment such as "I love it". Thus, the results partially support hypothesis 3 in which episodic ads would generate more of all four types such as attachment, experiential, empathic and self-related comments. Not only there were more ratio of comments expressing attachment to the episodic ads but equal ratio of the self-related comments were found on both types. Even though all the four factors have been suggested to be closely related to be persuasive in advertising research, the results of this study suggest that there are more relevant factors than others having an impact on persuasion according to the advertising types.

This raises an interesting question whether the episodic type of advertising actually facilitates a deeper emotional connection and empathic involvement in the ad and the brand through the shared stories depicted in the ads. An experimental study to clarify the cause and effect will be beneficial to the practitioners who want the viewers of their celebrity ad to be eventually felt attached to their brand. Also, as argued by many researchers, empathic emotion that comes from understanding and experiencing the situation of another person can be the best liaison to the brand liking while an attachment to a brand can make consumers pay more attention to and engagement in the brand. All four factors seem correlated on the surface but they may be more complex constructs than one as cause or effect of another. A path analysis will clear the relationships among them for better practical applications.

This study has several limitations in the process. Sentiment analyses using Google Bert were not used in the analysis as planned because the distinctive expressions in fandom needed an extensive level of training. Therefore, the sentiment of comments was analyzed only with the ratio of likes and dislikes over total views in this study. The future study needs to use better trained tool for the fandom specific vocabularies. Also, the Chi-square analyses showed a marginal significance level when all 6 comment types were compared together including 'other' type. If only 4 types such as attached, experiential, empathic and selfrelated were included or even each types was individually tested, the result would be more noticeable in the difference between the two types of ads. Further research is suggested to clarify the expected responses for each different ad type. The results also suggest exploring what 
mechanisms are behind the effect such as the relational types between the celebrities and the viewers and how the effect manifest in the actual sales performance in the future research. Academically, this study posits a newer perspective to include the context SNS generated in understanding celebrity endorsed advertising effect. Recently, the match between the brand and the celeb has been the major issue in the studies as well as the earlier findings on expertise, trustworthiness and attractiveness as the main influential factors. However, both lines of research miss out the fact that consumers can get very diverse perceptions through SNS where celebrities expose and disclose their personality in various episodes. Thus, they can sense the authenticity of the celebrity more easily than before, which will result in their perception toward the ad and the brand. In addition, by using all BTS endorsed ads, this study could control all other possible variables such as brand level, product types, celebrities' personality and images can be controlled.

The old theories on celebrity endorsed ads limit the creativity of the contents. Since celebrities are perceived to be vulnerable to the risks like scandals and aggressive fans and antis, companies tend to focus on their pictural images of physical attractiveness or their expertise than the verbal expressions or rich stories. Such a tactic may be an overreaction in the era of SNS. For, viewers may process the ad already with much knowledge and experiences on the personalities and attitudes of the celebrities. Thus, practitioners need to utilize their prior experiences in the social media episodes in their ads, so the viewers can fully consume the ad contents enough to develop their attachment to the ad and the brand. With the direct interaction with the celebrity on SNS, companies can have higher possibility that their consumers miss the initial reaction to interpret and judge the authenticity of the celebrity and the brand, and jump right into the ad contents. Moreover, practitioners can overcome the possible risks of the celebrity endorsement such as any reduced effect resulting from celebrity's multiple endorsements of brands and the eclipse effect of overshadowing the brand.

In short, by utilizing episodic contents from SNS to their celebrity endorsed ads, practitioners can achieve the advantage of getting viewers' strong engagement in their contents as well as producing more creative contents. Otherwise, they can limit their goal to utilizing the popularity of the celebrity in their ads.

〈Received December 14. 2020〉

〈Accepted January 18. 2021〉

\section{References}

Bergkvist, Lars (2017), "Celebrity trait transference: when brands pick up endorsers' personality traits," International Journal of Advertising, 
36(5), 663-681.

Biswas, D., A. Biswas, and N. Das (2006), "The effects of celebrity and expert endorsements on consumer risk perceptions: The moderating role of consumer product knowledge," Journal of Advertising, 35(2), 17-31.

Bu, K. H. (1997), "The Effects of Creatives in Ads Liked by Consumers," Korean Journal of Advertising, 8(1), 129-153.

Campbell and Kirmani (2000), “Consumers' Use of Persuasion Knowledge: The Effects of Accessibility and Cognitive Capacity on Perceptions of an Influence Agent," Journal of Consumer Research, 27(1), 69-83.

Charles, Reccia N., and Nazly K. Nardi (2015), "Brand Endorsement and COO: An Exploration of the Value of Multicultural Celebrity Brand Endorsers," Journal of Business Diversity, 15(2), 102-109.

Choi, S. M., W. N. Lee, and H. J. Kim. (2005), "Lessons from the rich and famous: A cross-cultural comparison of celebrity endorsement in advertising," Journal of Advertising, 34(2), 85-98.

Erdogan, Z. B., M. J. Baker, and S. Tagg. (2001), "Selecting celebrity endorsers: The practitioner's perspective," Journal of Advertising Research, 41(3), 39-48.

Gupta, Vishwas (2017), "Celebrity Endorsement

- An Analysis of Brand Image and Celebrity Image," International Journal of Applied Marketing and Management, 2 (2), 40-46.
Ilicic, Jasmina and Cynthia M. Webster (2014), "Eclipsing: When Celebrities Overshadow the Brand," Psychology \& Marketing, 31 (11), 1040-1050.

Kamins, M. A., and K. Gupta. (1994), "Congruence between spokesperson and product type: A matchup hypothesis perspective," Psychology \& Marketing, 11 (6), 569-586.

Kantar Millward Brown, China BrandZ and Celebrity Z (2020), “The State of Influencer Marketing 2020: Benchmark Report," https://influencermarketinghub.com/ influencer-marketing-benchmark-report2020/.

Kim, S., K. C. Wang, and T. H. Ahn. (2013), "Which endorser and content are most influential in Korean restaurant promotions?" International Journal of Hospitality Management, 33, 208-218.

Knoll, Johannes and Jörg Matthes (2017), “The effectiveness of celebrity endorsements: a meta-analysis," Journal of the Academy \& Marketing Science, 45, 55-75.

Lynch, J., and D. Schuler. (1994), “The matchup effect of spokesperson and product congruency: A schema theory interpretation," Psychology \& Marketing, 11(5), 417-445.

Maren Becker, Nico Wiegand, and Werner Reinartz (2019), “Does It Pay to Be Real? Understanding Authenticity in TV Advertising," Journal of Marketing, 83(1), 24-50. 
Popescu, Gheorghe H. (2014), “THE Economic Value of Celebrity Endorsement: A Literature Review," Management and Financial Markets, 9(4), 119-124.

Roozen, I., and C. Claeys (2010), "The relative effectiveness of celebrity endorsement for print advertisement," Review of Business and Economics, 55(1), 76-89.

Rossiter, John R., and Ale Smidts (2012), "Print advertising: Celebrity presenters," Journal of Business Research, 65(6), 874879.

Schimmelpfennig, Christian (2018), "Who is the Celebrity Endorser? A Content Analysis of Celebrity Endorsements," Journal of International Consumer Marketing, 30(4),
220-234.

Stout, P. A. and R. T. Rust (1993). "Emotional Feelings and Evaluative Dimensions of Advertising: Are They Related?” Journal of Advertising, 12(1), 61-71.

Till, Brian D., and Michael Busler (2000), "The Match-Up Hypothesis: Physical Attractiveness, Expertise, and the Role of Fit on Brand Attitude, Purchase Intent and Brand Beliefs," Journal of Advertising, 29 (3), 1-13.

Tripp, C., Jensen, T., \& Carlson, L. (1994), "The effects of multiple product endorsements by celebrities on consumers' attitudes and intentions," Journal of Consumer Research, 20(4), 535-547. 


\section{〈Appendix〉}

$\langle$ Appendix 1〉 BTS, All the endorsed brands and PR

\begin{tabular}{|c|c|}
\hline Company & Brand campaigns \& PR \\
\hline Namyang & French café K’hawah \\
\hline Lotte Hotel & Lotte Duty Free \\
\hline \multirow{7}{*}{ PUMA Korea } & PUMA 2015 WINTER : PLAY WARM \\
\hline & PUMA Blaze \\
\hline & PUMA BOG SOCK X BTS \\
\hline & PUMA Platform \\
\hline & PUMA X BTS COURT STAR \\
\hline & PUMA Striker Long Down \\
\hline & PUMA Turin \\
\hline \multirow{6}{*}{ SK Telecom } & SK Telecom \\
\hline & SK T Data coupon \\
\hline & SK varieT \\
\hline & NUGU \\
\hline & SK Telecom T World (with GFriend) \\
\hline & SK Telecom T Global \\
\hline SMART F\&D & SMART school uniform \\
\hline GENESIS & BBQ fried chicken \\
\hline VT COSMETIC & VT COSMETIC L'ATELIER \\
\hline L\&P COSMETIC & MEDIHEAL X BTS (Facial Mask Sheet) \\
\hline \multirow{2}{*}{ KB Kookmin Bank } & KB Bank \\
\hline & Liiv APP \\
\hline Netmarble Corporation & BTS World \\
\hline LG Electronics Inc. & G7 ThinQ \\
\hline The Coca-Cola Company & 2018 RUSSIA Worldcup Coca-cola \\
\hline \multirow{4}{*}{ Hyundai Motor Company } & Palisade \\
\hline & EARTH DAY \\
\hline & Positive Energy \\
\hline & Ionic \\
\hline \multirow{2}{*}{ Kyung Nam Pharm } & LEMONA X BTS \\
\hline & BTS LEMONA vitamin drink \\
\hline \multirow{3}{*}{$\begin{array}{l}\text { SAMSUNG } \\
\text { ELECTRONICS }\end{array}$} & Galaxy S20 (BTS Edition) \\
\hline & Galaxy Z Flip \\
\hline & Galaxy Note 20 \\
\hline \multirow{2}{*}{ Bodyfriend } & Bodyfriend PHANTOM Medical \\
\hline & Bodyfriend PHANTOM 2 cool \\
\hline \multirow{3}{*}{ Lotte Chilsung Beverage } & Chilsung cider \\
\hline & Chilsung cider peach \\
\hline & Chilsung cider green tangerine \\
\hline baskin robbins & baskin robbins ice cream \\
\hline Yahoo japan & Yahoo! Wi-Fi \\
\hline KBS & KBS NOON \\
\hline \multirow{6}{*}{ FILA } & FILA OAKMONT TR \\
\hline & FILA BARRICADEXT97 \\
\hline & RAYTRACER \\
\hline & PROJECT 7 \\
\hline & FILA ON THE STREET \\
\hline & Since 1911 FILA HERITAGE \\
\hline unicef Korea & LOVE MYSELF' Global Campaign \\
\hline Formula E & ABB FIA Formula E Championship \\
\hline \multirow{2}{*}{ Seoul, Korea } & BTS's Seoul Life \\
\hline & SEOUL TOURISM ORGANIZATION \\
\hline
\end{tabular}

